\title{
RETRACTED ARTICLE: Extract from the brown seaweed Ascophyllum nodosum as an elicitor of resistance to Fusarium oxysporum f. sp. radicis-lycopersici in tomato
}

\author{
Naser Panjehkeh · Javad Abkhoo
}

Received: 5 January 2016/Accepted: 4 February 2016/Published online: 17 February 2016

(C) Springer Science+Business Media Dordrecht 2016

The above article published online in Biotechnology Letters has been retracted at the request of the Editorin-Chief because substantial parts were simultaneously submitted to and published by the Journal of Applied Phycology "Control of Phytophthora melonis damping-off, induction of defense respnses, and gene expression of cucumber treated with commercial extract from Ascophyllum nodosum" Apr 2016, Volume 28, 1333-1342, DOI 10.1007/s10811-015-0693-3.

The tables and figures listed below that were submitted and published by Biotechnology Letters, referred to as A below, were exactly the same as published in J Appl Phycol (referred to as B below) with the senior author, J Abkhoo, having simply copied the data from the earlier paper and then claiming that the data had been produced using an entirely different set of experiments. No satisfactory

Electronic supplementary material The online version of this article (doi:10.1007/s10529-016-2061-z) contains supplementary material, which is available to authorized users.

N. Panjehkeh $(\square)$

Department of Plant Protection, Faculty of Agriculture,

University of Zabol, Zabol, Iran

e-mail: naserpanjehkeh@gmail.com

\section{J. Abkhoo}

Institute of Plant Biotechnology, University of Zabol,

Zabol 98617, Iran

e-mail: javad.abkhoo@yahoo.com explanation was received from Dr Abkhoo in spite of several requests to explain the duplication.

Table 1 in A gives exactly the same values as Table 3 in B.

Table 2 in A gives the same values as Table 4 in B but with the value of 1 being added to each value.

Table 3 in A gives exactly the same values as Table 5 in B (only with rounded numbers).

Table 4 in A gives exactly the same values as in Table 6 in B (with rounded values).

Figure 1 in A gives exactly the same values as Figure 1 in $\mathrm{B}$.

Figure 2 in A gives exactly the same values as Figure 2 in B.

Figure 3 in A, of which there are four parts, is exactly the same with all parts of Figure 3 in B.

There is no accusation of falsehood levelled against Dr Panjehkeh, the co-author of the paper, as he appears to have been only involved with the writing of the paper. The University of Zabol are currently undertaking an investigation into the conduct of Dr Abkhoo. "The online version of this article contains the full text of the retracted article as electronic supplementary material." 